\title{
Endocrine resistance in breast cancer: new roles for ErbB3 and ErbB4
}

\author{
Robert L Sutherland $d^{* 1,2}$ \\ See related research by Hutcheson et al., http://breast-cancer-research.com/content/13/2/R29
}

\begin{abstract}
Endocrine resistance is a major limitation to the successful treatment of estrogen receptor-positive $\left(E R^{+}\right)$breast cancer, and the EGFR (epidermal growth factor receptor) and ErbB-2 receptor tyrosine kinases are involved in this process. A recent study now implicates the other two ErbB family members, ErbB-3 and -4. Exposure of $E R^{+}$breast cancer cells to the pure antiestrogen, fulvestrant, increased levels of ErbB-3 or ErbB-4 and sensitivity to the growth-stimulatory effects of heregulin $\beta 1$, a potent ligand for these receptors. Thus, the initial growth-inhibitory effects of fulvestrant appear compromised by cellular plasticity that allows rapid compensatory growth stimulation via ErbB-3/4. Further evaluation of pan-ErbB receptor inhibitors in endocrine-resistant disease appears warranted.
\end{abstract}

\section{Introduction}

A major contributor to the significant recent decline in breast cancer mortality is the use of adjuvant endocrine therapy. However, the overall efficacy of tamoxifen, aromatase inhibitors, and the pure antiestrogen, fulvestrant, is limited by de novo and acquired resistance. The article by Hutcheson and colleagues [1] in the previous issue of Breast Cancer Research further develops our understanding of the role of the ErbB family in endocrine resistance by providing new insights into the roles of ErbB-3 and -4 in modulating sensitivity to fulvestrant.

Since endocrine resistance may compromise the effective treatment and potential cure of up to $25 \%$ of all breast cancers, defining the mechanisms of endocrine resistance has been a major research focus. This body of research identifies a wide range of biological mechanisms

\footnotetext{
*Correspondence: r.sutherland@garvan.org.au

'Cancer Research Program, Garvan Institute of Medical Research, 384 Victoria

Street, Darlinghurst, Sydney, NSW 2010, Australia

Full list of author information is available at the end of the article
}

that can confer endocrine resistance in vitro. These include the following: loss of estrogen receptor-alpha $(E R \alpha)$ expression and expression of truncated isoforms of $E R \alpha$ and ER $\beta$; post-translational modification, particularly phosphorylation of ER $\alpha$; increased activity of other transcription factors, including AP1 and c-Myc; deregulation of ER coactivators; and increased receptor tyrosine kinase signaling with resultant activation of the ERK and PI3K pathways and deregulation of the cell cycle, cell survival, and apoptotic machinery [2]. Although the direct relevance of these in vitro mechanisms to endocrine resistance in the clinic is far from clear, data accumulated in recent years provide strong evidence for a direct role for ErbB-2.

Since the initial observation that increased levels of both the epidermal growth factor receptor (EGFR/ ErbB-1) and ErbB-2 activate an autocrine growth-stimulatory pathway in tamoxifen-resistant MCF-7 cells [3], a number of laboratories have replicated and extended these findings. Thus, upregulation of ErbB-1 and -2 are common features of endocrine-resistant breast cancer cells, overexpression of these receptors confers insensitivity to endocrine agents in xenograft models and in patients whose tumors overexpress these receptors, and these effects can be attenuated by therapies that target ErbB receptors in combination with tamoxifen (see [1] for references). The article by Hutcheson and colleagues [1] extends these concepts to the other two members of the ErbB family.

\section{Potential role of ErbB-3/4}

Like EGFR and ErbB-2, ErbB-3 and -4 are transcriptionally repressed by estrogen [4], and there is evidence of coregulation of the ER and ErbB pathways [5], the loss of which, in the case of ErbB-2, contributes to endocrine resistance [6]. ErbB-3 and -4 can form homodimers, but whereas ErbB-4 homodimers are active, ErbB-3 has impaired kinase activity and is active only when dimerized with another family member [7]. Whereas EGFR is activated by EGF and related growth factors, ErbB-3 and -4 are receptors for the neuregulins (NRGs) [7]. In breast cancer, the most important ligand appears to be heregulin 
$\beta$ (NRG2), which, when administered to MCF-7 cells, induces a hormone-independent phenotype [8]. Although the evidence for a role for the heregulins in endocrine resistance implies a role for ErbB-3 and -4, the mechanisms are not well defined.

Hutcheson and colleagues [1] addressed this issue by exposing four $\mathrm{ER}^{+}$breast cancer cell lines to fulvestrant for 7 days. Although the responses as measured by a spectrum of cell proliferation and cell signaling endpoints showed some heterogeneity, a number of definitive conclusions were drawn. In support of earlier observations, fulvestrant treatment reduced ER $\alpha$ protein and ERmediated gene expression (progesterone receptor mRNA and cyclin D1 protein) and cell proliferation (cell number and Ki67 staining) in all four cell lines. This was accompanied by increased ErbB-3 (MCF-7, T47D) and -4 (BT474, MDAMB361) protein levels (but not mRNA levels) and enhanced basal phosphorylation of both receptors and ERK1/2.

Administration of HRG $\beta 1$ alone induced the expected activation of ErbB-3 and -4, ERK1/2, and AKT, although the effects on proliferation were varied. However, in the presence of fulvestrant, all four cell lines demonstrated enhanced sensitivity to HRG $\beta 1$ as measured by ErbB receptor, ERK1/2, and AKT phosphoryation; recovery of cyclin D1 expression; and enhanced proliferation. Notwithstanding some differential effects in the four cell lines, the data are strongly supportive of the authors' conclusions that antihormones, while inducing potent growth-inhibitory activity in $\mathrm{ER}^{+}$breast cancer cells, simultaneously induce and activate growth factor pathways that override the initial response and render the cells refractory to the inhibitory effects of fulvestrant.

These data are in good agreement with those of recent publications demonstrating that ErbB-3 is activated in tamoxifen-resistant [9] and fulvestrant-resistant [10] cells and that downregulation of ErbB-3 abrogates ErbB-2mediated tamoxifen resistance [9]. However, further work is needed to clarify the role of ErbB-4. Lykkesfeldt and colleagues [10] reported that this receptor is downregulated in fulvestrant-resistant MCF-7 cells, whereas others report upregulation in tamoxifen-resistant cells [11]. There are also inconsistent data on whether ErbB-4 is estrogen-induced [12] or antiestrogen-induced [1] and whether this is mediated at the transcriptional or posttranscriptional level.

\section{Conclusions}

The study by Hutcheson and colleagues raises a number of important issues relating to further defining mechanisms of endocrine resistance and to the identification of new therapeutic targets for future clinical testing. Their hypothesis-testing approach identifies two new targets but raises the question 'How many targets are there?' Given that ErbB-3 and -4 were upregulated at the protein level and not the mRNA level, a more global set of approaches to kinase and kinase substrate identification [13] in endocrine-resistant disease may yield a broader range of targets. Equally important is the translation of these data to the clinic. Although combinations of antihormones and growth factor inhibitors have shown great promise in experimental systems, they have, to date, been relatively disappointing in the clinic [14]. Thus, defining new mechanisms, new targets, and companion biomarkers that aid in patient selection remains a high priority. Given the current data [1], broadspectrum ErbB inhibitors and antibodies that inhibit ErbB heterodimerization [15] warrant further detailed evaluation in endocrine-resistant disease.

\section{Abbreviations}

EGFR, epidermal growth factor receptor; ER, estrogen receptor; NRG, neuregulin.

\section{Competing interests}

The author declares that he has no competing interests.

\section{Acknowledgments}

Research in the author's laboratory is supported by National Health and Medical Research Council of Australia Program Grant 535903 and Research Fellowship 427601, the Cancer Institute NSW Program Grant 10/TPG/1-04, the Australian Cancer Research Foundation, the Petre Foundation, and the RT Hall Trust.

\section{Author details}

'Cancer Research Program, Garvan Institute of Medical Research, 384 Victoria Street, Darlinghurst, Sydney, NSW 2010, Australia. ${ }^{2}$ St Vincent's Clinical School, Faculty of Medicine, University of New South Wales, Sydney, NSW 2052, Australia.

Published: 20 May 2011

\section{References}

1. Hutcheson IR, Goddard L, Barrow D, McClelland RA, Francies HE, Knowlden JM, Nicholson RI, Gee JM: Fulvestrant-induced expression of ErbB3 and ErbB4 receptors sensitizes ER-positive breast cancer cells to heregulin beta1. Breast Cancer Res 2011, 13:R29.

2. Musgrove EA, Sutherland RL: Biological determinants of endocrine resistance in breast cancer. Nat Rev Cancer 2009, 9:631-643.

3. Knowlden JM, Hutcheson IR, Jones HE, Madden T, Gee JM, Harper ME, Barrow D, Wakeling AE, Nicholson Rl: Elevated levels of epidermal growth factor receptor/c-erbB2 heterodimers mediate an autocrine growth regulatory pathway in tamoxifen-resistant MCF-7 cells. Endocrinology 2003, 144:1032-1044.

4. Revillion F, Pawlowski V, Lhotellier V, Louchez MM, Peyrat JP: mRNA expression of the type I growth factor receptors in the human breast cancer cells MCF-7: regulation by estradiol and tamoxifen. Anticancer Res 2003, 23:1455-1460.

5. Bates NP, Hurst HC: An intron 1 enhancer element mediates oestrogeninduced suppression of ERBB2 expression. Oncogene 1997, 15:473-481.

6. Hurtado A, Holmes KA, Geistlinger TR, Hutcheson IR, Nicholson RI, Brown M, Jiang J, Howat WJ, Ali S, Carroll JS: ERBB2 regulation by estrogen receptorPax2 determines tamoxifen response. Nature 2008, 456:663-666.

7. Hynes NE, Lane HA: ERBB receptors and cancer: the complexity of targeted inhibitors. Nat Rev Cancer 2005, 5:341-354.

8. Tang CK, Perez C, Grunt T, Waibel C, Cho C, Lupu R: Involvement of heregulin- $\beta 2$ in the acquisition of the hormone-independent phenotype of breast cancer cells. Cancer Res 1996, 56:3350-3358.

9. Liu B, Ordonez-Ercan D, Fan Z, Edgerton SM, Yang X, Thor AD: Downregulation of erbB3 abrogates erbB2-mediated tamoxifen resistance in breast cancer cells. Int J Cancer 2007, 120:1874-1882. 
10. Frogne T, Benjaminsen RV, Sonne-Hansen K, Sorensen BS, Nexo E, Laenkholm AV, Rasmussen LM, Riese DJ 2nd, de Cremoux P, Stenvang J, Lykkesfeldt AE: Activation of ErbB3, EGFR and Erk is essential for growth of human breast cancer cell lines with acquired resistance to fulvestrant. Breast Cancer Res Treat 2009, 114:263-275.

11. Ghayad SE, Vendrell JA, Larbi SB, Dumontet C, Bieche I, Cohen PA: Endocrine resistance associated with activated ErbB system in breast cancer cells is reversed by inhibiting MAPK or PI3K/Akt signaling pathways. Int $J$ Cancer 2010, 126:545-562.

12. Zhu Y, Sullivan LL, Nair SS, Williams CC, Pandey AK, Marrero L, Vadlamudi RK, Jones FE: Coregulation of estrogen receptor by ERBB4/HER4 establishes a growth-promoting autocrine signal in breast tumor cells. Cancer Res 2006, 66:7991-7998

13. Hochgräfe F, Zhang L, O'Toole SA, Browne BC, Pinese M, Porta Cubas A, Lehrbach GM, Croucher DR, Rickwood D, Boulghourjian A, Shearer R, Nair R,
Swarbrick A, Faratian D, Mullen P, Harrison DJ, Biankin AV, Sutherland RL, Raftery MJ, Daly RJ: Tyrosine phosphorylation profiling reveals the signaling network characteristics of basal breast cancer cells. Cancer Res 2010, 70:9391-9401.

14. Johnston SR: New strategies in estrogen receptor-positive breast cancer. Clin Cancer Res 2010, 16:1979-1987.

15. Baselga J, Swain SM: Novel anticancer targets: revisiting ERBB2 and discovering ERBB3. Nat Rev Cancer 2009, 9:463-475.

doi:10.1186/bcr2878

Cite this article as: Sutherland RL: Endocrine resistance in breast cancer: new roles for ErbB3 and ErbB4. Breast Cancer Research 2011, 13:106. 